as non-CTEPH and three MRI were considered non-diagnostic. MR lung perfusion was not performed in 11 patients due to impaired renal function or patient unable to tolerate breathhold. None of the surgically accessible disease was missed with either modality. The MR lung perfusion had a sensitivity of $96 \%$, specificity of $92 \%$, PPV of $87 \%$, NPV of $98 \%$ and accuracy of $94 \%$ for diagnosing CTEPH. Perfusion scintigraphy had a sensitivity of $93 \%$, specificity of $90 \%$, PPV of $83 \%$, NPV of $96 \%$ and accuracy of $91 \%$.

Conclusion Our results show that MR lung perfusion compared to 4-view static perfusion scintigraphy has an overall higher accuracy compared to perfusion scintigraphy and has a role in assessment of patients with suspected CTEPH.

\section{S24 INCIDENCE OF PERSISTENT PERFUSION DEFECTS FOLLOWING PULMONARY EMBOLISM: IMPACT ON PULMONARY ARTERY SYSTOLIC PRESSURE AT 6 MONTHS}

doi:10.1136/thoraxjnl-2011-201054b.24

S Fagerbrink, B Mukherjee, D Sirisena, N Salooja, L Howard. Hammersmith Hospital, Imperial College Healthcare, London, UK

Background The incidence of pulmonary hypertension (PH) after an episode of acute pulmonary embolism (PE) is thought to be up to $4 \%$. The incidence of persistent clot without $\mathrm{PH}$ is less clear. We evaluated the incidence of persistent perfusion defects in patients followed up after PE and assessed the impact on pulmonary arterial pressure measured by echocardiography.

Methods The clinical pathway for outpatient follow-up of patients with PE includes a nuclear medicine ventilationperfusion scan at 5 months post $\mathrm{PE}$. When this is positive, an echocardiogram is requested to look for evidence of $\mathrm{PH}$. A retrospective study of consecutive patients attending outpatient follow-up was carried out to determine the incidence of persistent perfusion defects and echocardiographic findings suggestive of $\mathrm{PH}$.

Results Ninety-three patients were identified between February 2009 and July 2011 and their clinical data were studied retrospectively. 59 patients $(63 \%)$ had persistent perfusion defects at 6 months. Of these 49 (83\%) underwent echocardiography of which 12 had undetectable tricuspid regurgitation (TR). In the remaining 37, pulmonary artery systolic pressure (PASP) could be estimated from the TR velocity. Results are shown in Abstract S24 figure 1 and are skewed due to the presence of patients with $\mathrm{PH}$. Median PASP (with IOR) was $32 \mathrm{~mm} \mathrm{Hg}(26-39)$. The shaded area shows the $95 \%$ CIs for the normal PASP $(28 \pm 9.8 \mathrm{~mm} \mathrm{Hg}$, mean \pm 2SD). Fourteen patients had estimated PASP above the normal range. Six patients were investigated with cardiac catheterisation

\section{Distribution of Estimated PASP}

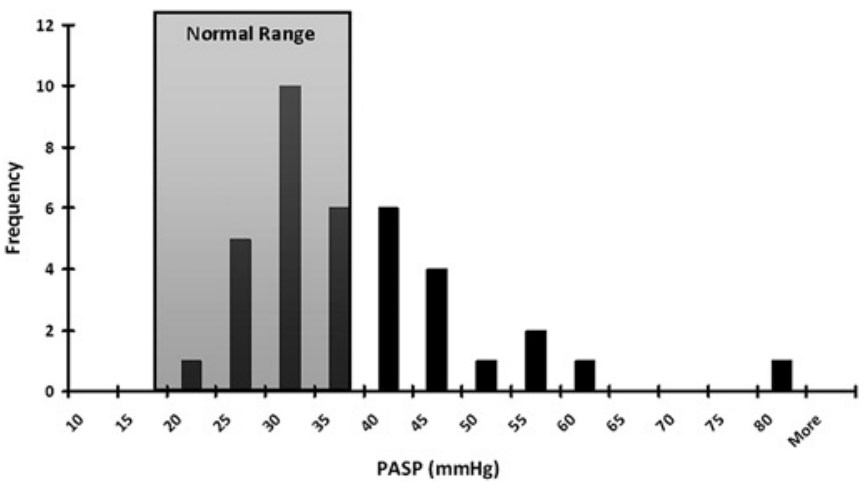

Abstract S24 Figure 1 Distribution of estimated PASP. and two were found to have chronic thromboembolic pulmonary hypertension (CTEPH). Borderline patients were kept under observation.

Conclusions Although the number of patients with CTEPH was in the expected range, the incidence of persistent perfusion defects following PE was surprisingly high in our cohort. Many of these patients fall in to a grey zone with borderline elevated pressures on echocardiography. The long-term outcomes of these patients and the physiological implications of their persistent perfusion defects are yet to be established and require further evaluation.

\section{S25 \\ INCIDENCE OF SURGICALLY TREATED PATIENTS WITH CHRONIC THROMBOEMBOLIC PULMONARY HYPERTENSION IN THE UK DURING THE LAST DECADE}

doi:10.1136/thoraxjnl-2011-201054b.25

${ }^{1} \mathrm{C} M$ Treacy, ${ }^{2} \mathrm{~J}$ Colledge, ${ }^{1} \mathrm{D}$ P Jenkins, ${ }^{1} \mathrm{~K}$ Page, ${ }^{1} \mathrm{~K}$ Sheares, ${ }^{1} \mathrm{~S}$ Tsui, ${ }^{1} \mathrm{~J}$ Dunning, ${ }^{1} \mathrm{~N}$ Screaton, ${ }^{1} \mathrm{D}$ Gopalan. ${ }^{1}$ Papworth Hospital NHS Trust, Cambridge, England; ${ }^{2}$ Enterprise Analytics Practice (EAP), London, England

Introduction Pulmonary endarterectomy (PEA) is the treatment of choice for patients with proximal chronic thromboembolic pulmonary hypertension (CTEPH). The UK has a single centre performing this operation and the program became nationally funded since 2000. Patients are referred from seven specialist pulmonary hypertension centres.

Method All 625 patients treated with PEA from 2000 to 2010 were mapped according to their home postcode at the time of PEA surgery. Primary care trusts (PCT's) were assigned from these home postcodes. The incidence rate of each PCT and overall incidence were analysed. Mapinfo software was used to generate the referral maps. Results The new patient incidence ranges from no referrals in 123 PCT's in 2000-2002 to 90 in 2008-2010. The most recent period shows highest referral rates for PEA. From our PEA data mapping analysis we have calculated that the incidence of operated patients was 0.4 million population in $2000(n=22)$ and 2 per million population in $2010(\mathrm{n}=122)$.

Conclusion There has been a fivefold increase in PEA activity in the UK over the last decade. The analysis of our data are limited to surgical cases. The current incidence of PEA in the UK is already higher than historical estimation of the incidence of all CTEPH (0.1-0.5/million, Fedullo, $N$ Engl J Med 2001). Since $30 \%$ of patients with CTEPH have distal disease distribution and some patients with proximal CTEPH do not proceed to surgery due to choice or comorbidities, the overall incidence of CTEPH is likely to be significantly higher than 2 per million/year and higher than previously suspected.

Abstract S25 Table 1 Patient Incidence/million population/period

\begin{tabular}{llllll}
\hline $\begin{array}{l}\text { Patient incidence } \\
\text { in PCT/million }\end{array}$ & $\begin{array}{l}\text { 2000-2002 } \\
\text { \# of PCT's }\end{array}$ & $\begin{array}{l}\text { 2003-2004 } \\
\text { \# of PCT's }\end{array}$ & $\begin{array}{l}\text { 2005-2006 } \\
\text { \# of PCT's }\end{array}$ & $\begin{array}{l}\text { 2007-2008 } \\
\text { \# of PCT's }\end{array}$ & $\begin{array}{l}\text { 2008-2010 } \\
\text { \# of PCT's }\end{array}$ \\
\hline 0 & 123 & 136 & 124 & 113 & 90 \\
0.1 to 2.4 & 16 & 13 & 10 & 18 & 12 \\
2.5 to 4.9 & 40 & 29 & 37 & 37 & 50 \\
5.0 to 7.4 & 10 & 9 & 19 & 15 & 20 \\
7.5 to 9.9 & 2 & 4 & 0 & 3 & 11 \\
10 to 35.6 & 3 & 3 & 4 & 8 & 11 \\
Total incidence/ & 0.56 & 0.65 & 1 & 1 & 1.6 \\
million & & & & & \\
\hline
\end{tabular}

Acknowledgements The authors would like to acknowledge the national pulmonary hypertension centres in the UK, Actelion Pharmaceuticals and the Cambridge Biomedical Center 